\title{
Limites da Gestáo Metropolitana e Impasses à Governança Cooperada Intermunicipal no Brasil
}

Norma Lacerda. Universidade Federal de Pernambuco, Pernambuco, Brasil. Suely Ribeiro. Universidade Federal de Pernambuco, Pernambuco, Brasil.

RESUMo | O pacto federativo brasileiro e a forma como vêm se estabelecendo as articulaçôes entre os atores políticos -o Estado, o mercado e a sociedade civil- têm representado limites à constituição de sistemas de gestão metropolitana e gerado impasses à cooperaçáo intermunicipal, acarretando conflitos de governança. Esses limites e conflitos tiveram, como desdobramentos, o desmonte das estruturas de planejamento metropolitano, o revigoramento do planejamento municipal e a fragmentação do espaço metropolitano com implicaçóes nos estudos sobre a metrópole. Para debater essas questóes, evidenciam-se: as debilidades do pacto federativo, responsáveis pela fragilização da gestáo e do planejamento metropolitanos; o alargamento do sistema de atores políticos e econômicos, no campo da governança, acarretando restriçóes à cooperação entre os municípios metropolitanos; e as interfaces entre os estudos urbanos e regionais e a mencionada problemática.

PALAVRAS-CHAVES | metropolização, gestão urbana, planejamento regional.

ABSTRACT | The Brazilian federation and the way in which forms of liaising have been established between political actors -the state, market and civil society- have represented limits to the forming of systems for metropolitan management, and have generated barriers to inter-municipal cooperation. This has led to conflicts of governance. Such limits and conflicts have unfolded as a result of the dismantling of the structures of metro $\neg$ politan planning, the re-vitalization of municipal planning, and the fragmentation of metropolitan space, with concurrent implications for research on the metropolis. In order to discuss these issues, evidence will be presented regarding the weakening of the Brazilian federation, which is responsible for the dismantling of metropolitan management and planning; the expansion of the system of political and economic actors, in the field of governance, which has led to restrictions on cooperation between metropolitan municipalities; and the interfaces between urban and regional studies in relation to the aforementioned problems.

KEY WORDS $\mid$ metropolization, urban management, regional planning.

Recibido el 5 de julio de 2012, aprobado el 5 de noviembre de 2012

E-Mail: Norma Lacerda,norma_lac@yahoo.com.br | Suely Ribeiro, suelyleal@terra.com.br 


\section{Apresentaçáo}

O trabalho presente objetiva refletir sobre os atuais padróes de gestão e governança metropolitana e suas implicaçóes nos processos de desenvolvimento e governabilidade das metrópoles brasileiras. Pretende-se avaliar os desafios e limites relativos à constituição de sistemas de gestáo cooperada intermunicipal, considerando os conflitos de governança, oriundos do pacto federativo brasileiro e da forma como se estabelecem as articulaçóes entre os atores políticos - o Estado, o mercado e a sociedade civil. Essas articulaçóes tendem a favorecer modos de governança em que predominam os interesses hegemônicos. De fato, apesar dos avanços decorrentes dos instrumentos de regulação criados pelo Governo Federal, a exemplo da Lei de Parceria Público-Privada (2004) e da Lei dos Consórcios (2005), ainda permanece um enorme vácuo no sistema de poder sobre os territórios metropolitanos.

Esse vácuo tem sido revelado pela recente literatura sobre a problemática da governança metropolitana no Brasil (Instituto de Pesquisa Econômica Aplicada [IPEA], 2011; Relatório Observatório das Metrópoles, 2009; Garson, 2009). Ademais, tal literatura aponta que essa questão não se resolve por meio de leis estaduais ou federais, que estabeleçam sistemas de planejamento metropolitanos verticalizados. As soluções delineadas oscilam entre: a defesa de um novo modelo federativo - que estabeleça mecanismos de cooperação vertical entre os entes federativos (União, Estados e Municípios) e articulaçóes horizontais entre os municípios metropolitanos; e a defesa de arranjos baseados nas iniciativas voluntárias intermunicipais, à conta do receio da perda da autonomia adquirida pelos municípios metropolitanos, desde a Constituição de 1988. Daí surgiu uma das hipóteses norteadoras deste trabalho: a governança metropolitana é muito mais uma questáo política do que uma questáo de modelo de gestão. Dito de outra forma: reformas institucionais, visando a transformar a organizaçáo do sistema de atores, com o intuito de estabelecer ou reforçar o poder metropolitano, podem favorecer a governança metropolitana. Mas, se este sistema político é fortemente concentrado ou fortemente disperso, torna-se um elemento desfavorável à governança.

Acresce que, as mudanças advindas da inserção do Brasil na economia globalizada, somadas àquelas oriundas do processo de descentralização político-administrativa $\mathrm{e}$

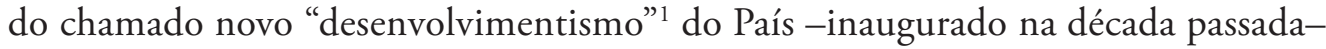
vêm provocando não apenas diversos arranjos de governança metropolitana, mas também, configurando outra ordem espacial metropolitana. Daí a segunda hipótese: na medida em que as estruturas de planejamento metropolitano -implantadas na década de 1970 - se foram desmontando, o planejamento municipal foi sendo reforçado, ao tempo em que o espaço metropolitano e os estudos sobre a metrópole

1 Bresser-Pereira publicou na Folha de Sáo Paulo (19/09/2004) um artigo intitulado O novo desenvolvimentismo, relacionando-o aos seguintes aspectos: maior abertura da conta comercial do país, feita de forma negociada; planejamento mais estratégico por parte do Estado; preocupação com a estabilidade macroeconômica, incluindo estabilidade de preços e equilíbrio do balanço de pagamentos e busca do pleno emprego; política macroeconômica capaz de inverter a equação perversa juros elevados e câmbio apreciado; desenvolvimento com recursos próprios de cada nação (não aceitação da estratégia de crescimento com poupança externa). 
se foram fragmentando, ora privilegiando análises sobre porçóes desse espaço, ora abordando problemáticas setoriais. Tal hipótese, em suas linhas centrais, aponta para a averiguação da existência ou não de um nexo entre as mudanças ocorridas na ação do Estado em termos de suas políticas globais e setoriais - com fortes implicações na estruturação do espaço metropolitano - e a produção científica.

Para alcançar o objetivo delineado e as hipóteses aventadas, o texto foi dividido em três partes. Na primeira, analisa-se a problemática da gestão das metrópoles brasileiras, evidenciando as debilidades do pacto federativo, responsáveis, em grande medida, pela sua fragilização político-administrativa e, como decorrência, pelo enfraquecimento do seu planejamento territorial. Na segunda parte, evidenciase a extensão do sistema de atores políticos e econômicos no campo da governança metropolitana, acarretando restriçôes à cooperação entre os municípios metropolitanos. Na terceira, enfatizam-se as interfaces entre a academia, mais particularmente entre os estudos urbanos e regionais, e a problemática metropolitana, no que concerne à gestão e à governança metropolitana.

\section{Problemática da gestáo metropolitana}

Em termos de gestão das metrópoles no Brasil fala-se, insistentemente, de um vácuo. Essa denúncia, porém, às vezes soa como uma espécie de saudosismo, em relação aos velhos tempos do regime militar, quando as metrópoles -oficializadas por Decreto-Lei de 1973- passaram a contar com instituiçóes responsáveis pelo governo metropolitano. É como se fossem esquecidas as mazelas decorrentes do próprio modelo político-administrativo centralizador da gestáo das metrópoles. Com efeito, devido a ele, foram alijados muitos municípios metropolitanos não alinhados politicamente ao mencionado regime, muitas ações perderam eficácia, e parte dos recursos financeiros foi irresponsavelmente desperdiçada. Esse padrão de gestão não apenas "fazia da região metropolitana uma criatura sob controle dos governos estaduais" (Rolnik, 2011, p. 1), mas, sobretudo, do Governo Federal.

A partir de 1988, passou-se a vivenciar um paradoxo. Por um lado, a Carta Magna conferiu aos Municípios brasileiros o status de entes federativos, o que lhes assegurou maior autonomia. Por outro, estabeleceu como uma das incumbências dos Estados, a definição das regióes metropolitanas. É evidente que, nesse contexto, qualquer iniciativa estadual de institucionalizar processos de gestáo metropolitana -em que o Estado tenha hegemonia- esbarrará na resistência dos municípios, que não admitirão perder parcela da sua autonomia.

Frente a esse paradoxo assiste-se, hoje, a uma situaçáo, no mínimo, bizarra. Um estudo elaborado por Ribeiro, Tavares da Silva e Martins Rodrigues (2011) evidenciou que, no Brasil, existem 15 espaços metropolitanos: São Paulo, Rio de Janeiro, Belo Horizonte, Porto Alegre, Brasília, Curitiba, Salvador, Recife, Fortaleza, Campinas, Manaus, Vitória, Goiânia, Belém e Florianópolis. Para tanto, foram levados em conta os seguintes aspectos: (i) tamanho e concentração (volume 
populacional, número de agências bancárias, volume total de operaçóes bancárias/ financeiras e massa de rendimentos); (ii) capacidade de centralidade (volume de serviços raros em nível nacional, a exemplo do movimento aeroportuário de passageiros); (iii) grau de inserção na economia nacional (número de empregos formais em atividades de ponta, como proxy da capacidade de inovação e incorporação de tecnologia); (iv) poder de direção (número de sedes de empresas classificadas entre as 500 maiores do país); e (v) gestáo pública (capitais estaduais e capital federal).

Esses espaços metropolitanos, em 2010, abrigavam 36,30\% da população brasileira (190.732.694 hab.), centralizavam 62\% da capacidade tecnológica do País ${ }^{2}$ (Ribeiro, Tavares da Silva \& Martins Rodrigues, 2011) e concentravam 55\% do valor de transformaçáo industrial das empresas exportadoras. São esses os espaços considerados no presente trabalho, quando da análise dos atuais sistemas de gestáo metropolitana no Brasil.

Outro estudo, recentemente desenvolvido pelo IPEA (2011), constata que o Brasil conta com 37 "regióes metropolitanas" definidas por leis estaduais, e três regiốes integradas de desenvolvimento econômico (Rides) ${ }^{3}$, delimitadas por lei federal, cabendo à União elaborar e executar, para essas regiôes, planos de desenvolvimento econômico e social e de ordenação do território. Esse trabalho realça que muitas das 37 "regióes metropolitanas" não guardam relação com as características de um processo de formação de uma metrópole, não refletem políticas ou estratégias de desenvolvimento territorial e não se atrelam à gestáo das funçóes públicas de interesse comum, isto é, não foram acompanhadas pela criação de sistemas de gestão metropolitana.

Comparando-se o marco jurídico-institucional da gestão metropolitana em 26 Estados, o mencionado estudo revela que apenas 14 metrópoles foram criadas à luz de legislaçóes estaduais complementares, que instituem sistema de gestão, e somente 9 Estados instituíram fundos metropolitanos, associados a sistemas de gestão. Isto significa que, para uma parte importante das metrópoles, a gestáo metropolitana não passa de retórica, não se desdobrando em açóes coletivas metropolitanas. Afinal, a grande maioria dos municípios metropolitanos, apegados à autonomia municipal, permanece indiferente à realidade metropolitana. Daí a indagação: por que criar regiốes metropolitanas? Ela só tem sentido se acompanhada de transformaçóes em termos de organização do sistema de atores, de modo a estabelecer ou reforçar o poder metropolitano.

De tudo isso, conclui-se que, desde a Constituição de 1988, a União tem "lavado as mãos" diante da problemática da gestão metropolitana. Somente na década passada ocorreu, como se verá adiante, no contexto do novo "desenvolvimentismo" - caracterizado pela ampliação do Estado, uma tímida iniciativa com vista à retomada do debate. Ora, o papel da Uniáo frente a essa problemática é decisivo. Deve caber-lhe a definição de: (i) critérios mínimos para que um aglomerado urbano seja

2 A capacidade tecnológica foi mensurada de acordo com "o número de patentes, artigos científicos, populaçáo com mais de 12 anos de estudos e valor bruto da transformaçáo industrial (vTi) das empresas que inovam em produtos e processos" (Ribeiro et al., 2011, p. 187).

3 Até então foram criadas três Rides: do Distrito Federal e do Entorno (DF/GO/MG); do Polo Petrolina e Juazeiro (BA/PE); e da Grande Teresina (PI/MA). 
considerado uma metrópole ${ }^{4}$; (ii) princípios e diretrizes minimos a serem respeitados pelas estruturas administrativas de gestão metropolitana; e (iii) estratégias territoriais e financeiras que a influenciem positivamente.

O que se vem assistindo nas metrópoles brasileiras, é uma excessiva setorialização dos problemas comuns metropolitanos. Em muitas delas, veem-se iniciativas de criação de conferências e conselhos setoriais - notadamente nas áreas de saúde, transporte e meio ambiente (Comitês de Bacias Hidrográficas) -, assim como de consórcios intermunicipais.

A lei de consórcios públicos (instituída em 2005 e regulamentada em 2007) tem fomentado essas políticas setoriais. $\mathrm{Na}$ verdade, a cooperação intermunicipal vem servindo como panaceia para a solução da gestão metropolitana, afirmando-se como importante mecanismo do fortalecimento dos municípios. Nesse sentido, é apresentada como recurso eficaz do desenvolvimento do território, da gestáo pública, da solidariedade financeira, da consolidação da democracia e do revigoramento das estruturas locais. Pode-se afirmar, no entanto, que os territórios e as escalas de cooperação e gestão consorciada, no caso brasileiro, ainda se mostram bastante incipientes (Leal, 2004a e 2004b).

As dificuldades de cooperação entre municípios metropolitanos passam por vários fatores dentre os quais, merecem destaque, a natureza das estruturas organizacionais e administrativas e a cultura política brasileira. A regulamentação federativa circunscreve a atuação dos municípios aos territórios sobre os quais eles têm jurisdição. Isso tem implicaçóes importantes na gestão municipal, seja no sentido da eficácia da atuação das instâncias administrativas, seja no que diz respeito à esfera institucional e política. Os impactos sobre o cotidiano dos cidadãos são exemplificados em diversos conflitos, como no fato de o individuo não poder acessar um posto de saúde do outro lado da sua rua, se este pertencer a outro município. O mesmo acontece com a educação, com a segurança etc. Além disso, os arranjos institucionais e as açóes deles decorrentes fazem com que os prefeitos exerçam o controle político sobre o território municipal, sem compartilhar as açóes com municípios vizinhos, dado que elas redundam em frutos eleitorais.

Em suas linhas centrais, essas iniciativas contribuem para a perda da perspectiva de um desenvolvimento metropolitano integrado. Como exemplo, cite-se o fato dos planos metropolitanos de transporte náo dialogarem com os planos diretores municipais, especialmente no que se refere ao uso e ocupação do solo. Mesmo naqueles casos em que existem planos de desenvolvimento metropolitano, esses planos náo se constituem, em geral, em referenciais para os planos setoriais.

Todos esses conflitos, oriundos da estrutura federativa brasileira, permearam o debate sobre a "perversidade" do modelo de descentralização político-administrativa, tanto em nível institucional, quanto acadêmico, culminando com as proposiçóes contempladas na lei dos consórcios (Melo, 2000; Arretche, 2000). extremamente heterogêneas quanto ao grau de integração desses municípios ao fenômeno metropolitano" (Observatório das Metrópoles, 2009, p. 4). 
Somente em 2007, por meio do Decreto n 6.181, o Presidente da República, atendendo à recomendação do Comitê de Articulação Federativa, instituiu um grupo de trabalho a fim de elaborar propostas para o aperfeiçoamento da gestão das regióes metropolitanas, aglomeraçóes urbanas e microrregióes. Contudo, é importante registrar que a Subchefia de Assuntos Federativos (SAF), da Secretaria de Relaçóes Institucionais (SRI) da Presidência da República, defende um modelo baseado nas iniciativas voluntárias intermunicipais. A SRI receia que a coordenação estadual leve à perda da autonomia dos municípios metropolitanos. Em decorrência desse posicionamento, defende os consórcios como o modelo mais indicado para a gestão metropolitana (Observatório das Metrópoles, 2009). Esse não é o ponto de vista do Fórum Nacional de Entidades Metropolitanas (FNEM), criado em 1995, em Porto Alegre. Segundo o FNEM, os organismos estaduais "deverão apoiar e participar, quando o objeto exigir, de consórcios intermunicipais, porém, como um instrumento complementar à gestão metropolitana" (Apud Relatório Observatório das Metrópoles, 2009, p. 1).

Em 2004, surgiu a primeira proposta do Legislativo -Câmara dos Deputados-, no sentido de instituir diretrizes para a Política Nacional de Planejamento Regional e Urbano e criar o Sistema Nacional de Planejamento e Informaçóes Regionais e Urbanas. Tal proposta (Projeto de Lei $\mathrm{n}^{\circ} 3.460 / 2004$ ), de autoria do Deputado Walter Feldman (РsDв/Sáo Paulo), passou a ser conhecida como Estatuto da Metrópole. Esse Estatuto tem sido questionado, à conta da proposta de um único requisito, para que um conjunto de municípios seja considerado uma região (população), da não distinção das responsabilidades da União e das unidades regionais e urbanas, do não estabelecimento de disposiçóes pelas quais as unidades implantem seus sistemas gestores e, finalmente, da não previsão de uma sistemática orçamentária. $\mathrm{O}$ Estatuto da Metrópole foi arquivado, tendo sido solicitado o seu desarquivamento pelo autor do Projeto de Lei (Requerimento, no 705, de março de 2011). Desarquivado, por Ato da Mesa, a matéria retornou ao ponto em que havia parado, qual seja, sua análise pela Comissão Especial.

No que se refere aos 15 espaços metropolitanos acima referidos, cabe registrar que Florianópolis, apesar de ser um espaço metropolitano, segundo os critérios do estudo do Observatório das Metrópoles (2009), foi instituída como metrópole pelo governo estadual, em 1998, e extinta, em 2007. Não contou com uma estrutura organizacional, muito embora o Estado de Santa Catarina detenha uma longa experiência de associativismo municipal. Quanto a Brasília, capital federal, é um caso à parte, pois conforma uma Regiáo de Desenvolvimento Integrado do Distrito Federal e do Entorno (DF/GO/MG).

Em relação às demais nove metrópoles (São Paulo, Rio de Janeiro, Belo Horizonte, Porto Alegre, Curitiba, Recife, Salvador, Fortaleza e Belém), haviam sido institucionalizadas pela Lei Complementar $\mathrm{n}^{\circ} 14$, de 1973, e induzidas a implementar as respectivas estruturas de gestáo metropolitana. Na segunda metade dos anos 1970, suas entidades metropolitanas atuaram intensamente, em consonância com a política nacional de desenvolvimento urbano e, inclusive, com o II Plano Nacional de Desenvolvimento (1975-1979), que reconhecem as metrópoles como lócus da produção industrial. 
A partir da primeira metade da década de 1990, essas estruturas começaram a desmoronar e os Estados passaram a estabelecer suas regióes metropolitanas. Nesse contexto, as nove metrópoles mencionadas são reafirmadas por meio de leis estaduais e outras quatro (Campinas, Manaus, Vitória e Goiânia) foram criadas. Essas 13 regióes metropolitanas institucionalizaram, nos anos de 1990, modelos de gestão diferenciados. Em suas linhas centrais, avançaram no que diz respeito à composição das forças sociais, ao incorporarem nos respectivos conselhos e/ou câmaras setoriais, representantes da sociedade civil. Mas, a análise empreendida pelo IPEA (2011), acerca das legislaçóes estaduais complementares - existentes em 31 de janeiro de 2010 -, assinala que, em cinco dos Estados que abrigam essas 13 regióes, não foram encontradas referências normativas referentes à criação de fundos metropolitanos.

Não resta dúvida de que as reformas institucionais, sobretudo aquelas que visam transformar a composiçáo do sistema de atores - participação da sociedade civil organizada (associaçóes civis e organizaçóes não governamentais) e a iniciativa privada stricto sensu- devem ser consideradas como sinais positivos, no sentido de avançar sobre a problemática da gestáo metropolitana. Todavia, a questáo central é o seu real funcionamento, e esse aspecto depende, essencialmente, do componente político.

Sabe-se, por exemplo, que a Região Metropolitana do Recife (RMR) possui um arcabouço institucional: o Sistema Gestor Metropolitano, formado pelo Conselho de Desenvolvimento da Região Metropolitana (Conderm), com suas Câmaras Técnicas, pelo Fundo de Desenvolvimento Metropolitano (Funderm) e pela Agência Condepe/Fidem 5 . Esta última é responsável não apenas pela elaboração de planos metropolitanos, mas também de planos para todas as microrregióes que conformam o Estado de Pernambuco. Ora, sabe-se que os arranjos institucionais metropolitanos - num contexto em que os Estados estabelecem as regras do jogo - funcionam de acordo com a importância que a gestão estadual a eles confere ou conforme a pressão dos municípios, em particular do Município núcleo, concentrador de poderes políticos e econômicos. No caso em pauta, o sistema gestor metropolitano encontra-se paralisado. O Governo Estadual não tem reunido o Conderm nem para discutir as intervençóes relativas à Cidade da Copa de 2014, ação com impactos relevantes na estrutura espacial da metrópole recifense. Aliás, esse grande projeto estratégico vem sendo desenvolvido por uma secretaria especial estadual, sem a participação da Condepe/Fidem. Ademais, o Governo do núcleo metropolitano tem revelado pouco poder político em relação ao próprio município. Como ensina Lefrève (2004, p. 25), “a resolução da questão de dominação do município

5 A Fundação de Desenvolvimento da Região Metropolitana do Recife (Fidem) foi instituída em 1975, como órgáo vinculado à Secretaria de Planejamento do Estado, com a incumbência de funcionar como órgão de apoio técnico e administrativo aos Conselhos Deliberativo e Consultivo da RMR instalados. Nesse mesmo ano, foi instituído o Fundo de Desenvolvimento da Região Metropolitana do Recife. Em 1999, a Fidem transformou-se na Fundação de Desenvolvimento Municipal (Fidem), mediante a fusão com a Fundação de Desenvolvimento Municipal (Fiam). Em 2003, transformouse em Agência de Planejamento e Pesquisa do Estado de Pernambuco - Agência Condepel Fidem, por meio da fusão com o Conselho de Desenvolvimento de Pernambuco (Condepe). De mero complemento da livre e eficiente ação do mercado, o Estado passou a ser compreendido novamente como um agente relevante para o desenvolvimento, retomando a importância do seu papel, como agente regulador e de planejamento. 
núcleo é um elemento chave no sucesso ou fracasso de um projeto metropolitano", dominação respaldada na concentraçáo de poderes econômicos e políticos.

O caso da RMR assinala, fortemente, que o grau de atuaçáo de qualquer sistema gestor depende de lideranças políticas conscientes da sua importância, e capazes de reforçar um poder metropolitano compartilhado com os municípios ou, pelo menos, com a maioria deles.

A análise desenvolvida por Lefevre (2004) sobre o desempenho da gestão em 11 metrópoles (Barcelona, Berlim, Lisboa, Londres, Madri, Manchester, Milão, Montréal, Roma, Stutgart e Toronto), considerou seis elementos: (i) ator portador de identidade, podendo ser um líder político da metrópole ou um grupo político; (ii) estrutura politica, revelada por meio de um arcabouço institucional; (iii) estrutura administrativa, necessária ao desenvolvimento de estudos e planos; (iv) mobilização da sociedade civil, importante para conferir legitimação ao projeto metropolitano; (v) documentos que simbolizem a ideia de metrópole; e (vi) açóes concretas compartilhadas.

O estudo revela que Londres e Barcelona ocupam, respectivamente, o primeiro e o segundo lugar no ranking das relacionadas metrópoles. O Prefeito de Londres, K. Livingstone se envolveu diretamente na elaboração de diversas estratégias, capazes de mobilizar as forças sociais londrinas (sociedade civil, empresários...), de modo a viabilizar um projeto metropolitano. Esse projeto, portanto, é centrado em um líder político. No caso de Barcelona, o plano estratégico - dos finais dos anos de 1980, com o intuito de preparar a metrópole para os Jogos Olímpicos de 1992 - foi comandado por uma estrutura política particular: um conselho de 300 membros, presidido pelo Prefeito de Barcelona e apoiado por nove órgãos técnicos. A elaboração desse plano significou uma imensa mobilizaçáo da sociedade civil, sindicatos, universidades, empresários etc. Nesse caso, a fragmentaçáo político-institucional entre a Comuna Central e a Generalitat, pesou sobre a constituição de uma liderança política metropolitana.

Essa avaliação evidencia a necessidade de enfrentar os bloqueios à constituição das metrópoles enquanto espaço político, base para a construçáo de um projeto metropolitano capaz de mobilizar os atores - Estado, mercado e sociedade -, com vista ao equacionamento dos problemas que afligem as metrópoles. Sem essa construção, as metrópoles permanecerão como arranjos funcionais que atendem, preferencialmente, às lógicas privatistas e fragmentadas dos atores econômicos e políticos, que se apropriam dos espaços metropolitanos como objeto de lucro e poder de dominação.

No caso brasileiro, para o enfrentamento desses bloqueios, torna-se urgente a constituição de uma agenda institucional de reforma do Estado, por meio da qual o ente metropolitano passa a assumir a capacidade de gestáo e de regulaçáo, em sintonia com os entes federados. Isso levaria à retomada de uma estrutura administrativa específica, necessária à elaboração de estudos e planos capazes, inclusive, de simbolizar a metrópole nos termos acima referidos e, como desdobramento, contribuir para a construção da metrópole como espaço político.

A análise acima apresentada ressalta a dimensão da complexidade do federalismo brasileiro que, embora tenha contribuído com largos passos para a democratização do sistema de gestão participativo em nível institucional, por meio da descentralização 
do Estado, levou, do ponto de vista metropolitano, ao desmantelamento dos instrumentos de planejamento metropolitano, e do incipiente arcabouço de gestáo e governança instaurado pelas agências de planejamento metropolitano. Assim, apesar dos esforços técnicos em criar, nos organogramas institucionais, conselhos e outros instrumentos de cooperação, a gestão metropolitana, no caso brasileiro, ainda sobrevive no bojo da fragmentação do território e de poucas experiências exitosas.

\section{Impasses da governança metropolitana democrática}

Os padróes de governança das metrópoles brasileiras, a partir dos quais os atores econômicos e sociais fazem sua inserção, podem ser agrupados em pelo menos quatro tipos preliminares. O primeiro refere-se ao tipo clássico ou tradicional de articulação com o Estado, mediante o qual os segmentos das elites mantêm padróes de governança de forma patrimonialista e clientelista. Nesse caso, transitam clandestinamente e por fora do espaço democrático, em nível institucional, defendendo interesses eleitorais em causa própria, ou de grupos econômicos. $\mathrm{O}$ segundo tipo concerne aos territórios democrático-populares, em que se fazem representar, além dos segmentos populares, as elites modernas (capital imobiliário, comercial e de serviços) e o setor público (dirigentes e quadros técnicos). O terceiro diz respeito à governança corporativa, cujo traço principal é a associação entre o público e o privado (representado por fraçóes das elites), nas formas de gestão compartilhada (parcerias). Finalmente, o quarto padrão de governança reporta-se ao tipo neoliberal, a partir do qual as articulaçóes dos agentes econômicos se fazem diretamente por meio do mercado. Os dois últimos conduzem a uma tendência de direcionamento à privatização do Estado (Leal, 2011).

Para Christian Lefèvre (2004), o principal desafio da governança metropolitana é ir além da fragmentação dos interesses dos atores sobre o território metropolitano, particularmente em um contexto de abertura do sistema de atores. Tal sistema -outrora dominado pela esfera pública- passa a ter uma natureza policêntrica, onde os atores econômicos e sociais ocupam um lugar importante. Ademais, ele enfrenta o desafio de processos de descentralização político-administrativa, que vêm transformando as relaçóes entre as coletividades territoriais metropolitanas.

Essa questão remete ao conceito de governança, aqui entendido como um sistema de articulação entre os atores e os arranjos políticos deles decorrentes (Dallabrida, 2012 e 2011). Observe-se que, os sistemas de governança metropolitana instaurados, no caso brasileiro, na década de 1970, além de terem o predomínio e o comando da esfera estatal, eram orientados segundo os princípios políticos do Estado centralizado, configurando uma governança do tipo clássico ou tradicional. Nela, a penetração dos interesses dos agentes econômicos e a representação de seus atores, nos espaços estatais, são intrínsecas à cultura política patrimonialista do Estado brasileiro. Por meio dela, as elites tradicionais vêm tendo o seu assento nas cadeiras do Parlamento e nas funções de direção do Estado, nas três esferas de governo.

A Constituição de 1988 possibilitou a formatação de sistemas de governança em que se fazem presentes territórios de poder democrático-popular, nos quais se insere a sociedade civil, sendo facultada a representação político-partidária e dos 
agentes econômicos, por intermédio da criação de canais de gestão participativa, a exemplo das conferências nacional, estaduais e municipais, dos orçamentos participativos, dos conselhos setoriais nas áreas da saúde, educação, criança e adolescência, entre outros. No caso da gestáo metropolitana, os formatos participativos de representação comportam dois tipos de limitaçôes principais: (i) um, de caráter democrático, propriamente dito, visto que a participação da sociedade civil ocorre de forma bastante limitada e residual; e (ii) o outro, decorrente da frágil (ou quase inócua) capacidade deliberativa dos mecanismos de gestáo, instituídos pelas agências governamentais. Existe, aliás, um ditado, segundo o qual "sem dinheiro ninguém manda!!!” Isso, conjuntamente com a questão federativa, tem sido um dos elementos de restrição à funcionalidade de uma governança democrática, na gestão das metrópoles brasileiras. Apesar disso, alguns municípios integrantes dessas regiôes, avançaram na constituição de mecanismos participativos de gestão e governança democrática, como os orçamentos participativos, os conselhos e as conferências (Leal, 2004a).

No entanto, mesmo considerando os avanços democráticos e a emergência, no cenário nacional, de inúmeras experiências municipais exitosas no campo da democracia participativa, tal cenário foi abalado, a partir dos anos noventa, pela febre do empreendedorismo, que se tornou uma prática sistemática de prefeitos, passando a compor a agenda de alguns governos locais das mais diversas tendências políticas, e fazendo emergir um novo formato de governança. (Leal, 2004b).

A base dessa governança é a virtualidade organizacional, fundada no pacto consensual entre os atores sociais, visando atrair investimentos econômicos do capital privado (Castells \& Borja, 1996). O discurso da cidade protagonista e maquiada é repassado pela figura de prefeitos carismáticos, cujo papel de liderança visa articular interesses dos diferentes atores sociais. Esse discurso passou a constituir um verdadeiro modismo no planejamento urbano municipal (Harvey, 1996).

Nesse contexto, as práticas de gestão compartilhada - por meio de parcerias entre o setor público e o privado - surgem como inovaçóes adotadas pelos gestores públicos, impulsionando profundas mudanças nas formas tradicionais de relacionamento entre a administração pública e o setor privado. Um novo tipo de relação contratual passa a contrapor-se à forma de governança clássica, onde havia uma separaçáo clara entre o papel regulador e planificador do Estado e o mercado. Doravante, o setor público age como gestor-contratante e, o setor privado, como contratado.

Esse padrão de governança corporativa faz-se presente por meio de formas diversas de concessão de serviços públicos, de práticas de privatização, e de parcerias financeiras para a construçáo de projetos de infraestrutura e equipamentos urbanos de grande porte. A interpenetração do público e privado se estabelece com a presença reguladora do Estado, mediante as benesses de isençóes fiscais, a usura do patrimônio público, o marketing, e a apropriação de espaços das cidades.

A governança corporativa configura-se num mecanismo de fortalecimento das corporaçóes globais, funcionando como uma das estratégias necessárias à mobilização de capacidades e oportunidades, com vistas ao pioneirismo em produtos e serviços, e à operacionalização com base na flexibilidade e eficiência, inclusive a financeira (Dupas, 2005). Essa configuração de governança tem implicaçóes na presença dos 
interesses econômicos dentro do aparelho de Estado, na sua crescente privatização, e na diminuição dos espaços de interesse público, em detrimento da sua função social.

A penetração dos interesses dos agentes econômicos e a representação de seus atores nos espaços públicos, não constituem um fato novo na patrimonialista cultura política do Estado brasileiro. Afinal, as elites tradicionais sempre estiveram presentes nas funçóes de direção do Estado, nas três esferas de governo onde, por meio de alianças eleitorais e no seio das administraçóes públicas constituíram engenharias políticas, à direita e à esquerda.

Paulatinamente, com o avanço da globalização, das mudanças tecnológicas e da reestruturação produtiva, novas fraçôes das elites emergiram no cenário nacional, originando outras formas de articulação entre Estado e mercado, particularmente nas grandes metrópoles. Nesse padrão de governança -tipo neoliberal-, as chamadas elites modernas passaram a fazer-se representar por intermédio do capital imobiliário, do industrial, vinculado ao capital internacional, dos segmentos financeiros e bancários, das grandes corporaçóes do comércio moderno e dos serviços especializados. Uma resultante desse processo é a fragilizaçáo do papel do planejamento metropolitano, o que vem contribuindo para um elevado grau de liberalismo, na forma de produção e apropriação do território das metrópoles.

A emergência dessas elites não eliminou a convivência do Estado com as antigas fraçóes da burguesia nacional-tradicional. Ao contrário, possibilitou a articulação de alianças que tendem, cada vez mais, a favorecer o poder de pressão dos grupos hegemônicos. A capacidade de influência desses atores econômicos, nas metrópoles, ampliou-se em todos os segmentos setoriais, particularmente com respeito às políticas de infraestrutura urbana.

É lamentável que as formas de gestão e governança das metrópoles, resultantes do processo de descentralização e democratização do País, não tenham tido força suficiente para retrair a influência das elites econômicas. Ao contrário, no contexto de abertura dos sistemas de governança corporativa, o que se observa é o acirramento da fragmentação dos interesses e dos atores sobre o território metropolitano e, em geral, o das cidades.

Esta fragmentação fragiliza o papel de lideranças no campo político-governamental, as quais, embora se apresentem como fortes no campo eleitoral, reduzem sua capacidade de comandar o processo de gestáo e de governança compartilhada, seja em nível metropolitano, seja em nível das administraçóes locais. Além do mais, essa fragmentação dificulta a mobilização da sociedade civil por meio das suas organizaçóes. E essa mobilização é essencial. Afinal, a governança metropolitana não pode, nem deve, ser resultado unicamente do "mundo político", dos poderes institucionalizados.

Tal questão remete a outra: à identidade metropolitana, mediante a qual, a governança metropolitana surge como legítima. Sabe-se que existem, nas metrópoles, diversas identidades históricas e territorialmente edificadas. Elas podem, ou não, favorecer a emergência e/ou consolidação de uma identidade metropolitana.

É importante enfatizar que os aspectos de natureza financeira e fiscal também estruturam as relaçôes entre atores, podendo inclusive causar conflitos entre os municípios, como é o caso da "guerra fiscal." Esta, provavelmente, tem sido 
prejudicial à emergência de metrópoles como territórios políticos. Essa questão, confrontada com a autonomia dos municípios no sentido de definirem impostos e taxas, náo é condizente com a solidariedade, base de uma governança metropolitana democrática, uma vez que estimula comportamentos não cooperativos.

$\mathrm{Na}$ atualidade, o alargamento do sistema de atores, no campo da governança metropolitana, emerge como forte restrição à cooperação intermunicipal, no nível institucional e político (Leal, 2008).

Tal ampliação ocorre, sobretudo, face à presença dos atores econômicos na governança das cidades, por meio da formação de corporaçóes pelo mercado, gerando uma acelerada concentração de poder, fundada na apropriação da produção capitalista do espaço urbano. A associação entre o capital financeiro e o capital imobiliário, e o papel do Estado na dotação de infraestrutura, vêm reforçando a função dos grandes centros urbanos como o lócus principal da acumulação urbana, com consequências danosas sobre a qualidade de vida em tais centros.

Os centros metropolitanos de maior porte são os mais sujeitos às pressóes do mercado, particularmente das empresas imobiliárias e construtoras, responsáveis pelos megaprojetos e pela infraestrutura, tornando os sistemas de gestáo metropolitanos inoperantes, e os espaços fragmentados. Essa fragilidade vem ampliando o lugar ocupado pelas açóes do capital - em particular, pelos segmentos que detêm o monopólio sobre os espaços urbanos (o capital imobiliário e o financeiro) -, os quais vêm conduzindo a cadeia da acumulaçáo urbana, sobretudo nos grandes centros metropolitanos. Nessas condiçóes, a governança metropolitana passa a ser guiada pela ausência do planejamento estatal, pela disputa entre os entes federados, pelos recursos da Uniáo, e pela pouca primazia dos instrumentos e mecanismos participativos de gestão democrática, no processo decisório sobre as açóes de interesse comum, que impactam as metrópoles. Exemplos dessa debilidade são os megaeventos, como a Copa do Mundo de Futebol de 2014 e, mais especificamente, os projetos infraestruturais a eles correlatos, com impactos no processo de estruturação espacial de muitas metrópoles brasileiras. Entre os possíveis impactos, salientam-se a fragmentação socioespacial, a intensificação do valor do solo urbano, a desconstituição dos laços de solidariedade das comunidades afetadas e a subutilização de parte dos equipamentos. Não sem razão, Alves (2011, p. 111) afirma que: "o Estado de direito tem se transformado em um Estado de exceção permanente. Em consequência, este regime biopolítico gera 'exceçóes urbanísticas' na cidade, tanto para o controle social, quanto para a expansão do capital.” Mais ainda, esse Estado de exceção tem tido implicaçóes nos estudos urbanos e regionais, como se verá mais adiante.

Se o sistema de gestão, presente em algumas metrópoles, já havia sido desmantelado após a Carta Magna de 1988, ele se dilui por inteiro diante da necessidade avassaladora do fortalecimento do empreendedorismo do mercado, em parceria cada vez mais estreita - com o Estado. O poder local tende a assumir essa lógica empreendedora, entrando em sintonia com o mercado e esvaziando as funçóes exercidas pelo sistema de planejamento e pelos mecanismos democráticos em vigor, a exemplo dos orçamentos participativos, conselhos e conferências (esses dois últimos, integrantes dos sistemas nacional, estaduais e municipais). 
Diante dos argumentos expostos, cabe questionar:

- Em que medida a ampliação do espaço de atuação dos agentes econômicos, nas metrópoles, leva a uma perspectiva de privatizaçáo do Estado e a um correlato esvaziamento do papel do planejamento urbano e metropolitano?

- De que forma se manifestam os indícios de certo oportunismo, por parte dos agentes econômicos no sentido de impor seus interesses hegemônicos, ante essa condição de possíveis financiadores da promoção do empoderamento dos cidadãos e da construção da cidadania?

- Como os setores populares urbanos e da sociedade civil em geral, identificados com o projeto democrático-popular, estão reagindo a essa provável acentuação da influência dos agentes econômicos nos processos de governança das metrópoles e cidades?

- Até que ponto há uma percepção, por parte dos movimentos e representaçóes da sociedade civil, de que a redução dos espaços institucionais de participação é compensada pelo comprometimento dos agentes econômicos com o empoderamento social?

- Quais as repercussóes dessa possível retração dos espaços participativos sobre o projeto democrático-popular?

Nessas condiçôes, indaga-se ainda:

- Para onde caminham os processos de governança das corporaçôes capitalistas, e quais as suas implicaçóes na estruturação espacial das metrópoles?

- Qual o papel das universidades, da pesquisa e da ciência e tecnologia frente à problemática metropolitana e, mais especificamente, sobre a gestão e governança urbana?

\section{Temática da gestáo/governança metropolitana na produçáo acadêmica}

A questão referente às interfaces entre a produção acadêmica e a gestão metropolitana estimula a averiguar-se: até que ponto essa problemática, em suas diversas dimensóes -econômica, política, social, administrativa, ambiental e cultural- tem mobilizado as instituiçóes de ensino e pesquisa a inserirem, no escopo dos programas de graduação e pós-graduação, a temática metropolitana.

A hipótese que se levanta neste trabalho, como registrado, é a de que no Brasil há uma estreita relação entre as mudanças ocorridas na ação do Estado, em termos de suas políticas globais e setoriais -com fortes implicaçóes na estruturação do espaço metropolitano- e a produção no campo cientifico. Isto é verdadeiro, sobretudo, na área de planejamento urbano e regional, face à sua estreita relação com o papel do Estado.

$\mathrm{Na}$ verdade, a problemática metropolitana, à conta da sua complexidade, representa um desafio teórico-metodológico que deve ser enfrentado pelas instâncias acadêmicas de planejamento, de modo a produzir aportes de investigação que 
levem em conta o novo formato do Estado e da produção do espaço da metrópole. $\mathrm{O}$ que se assiste -na maioria dos programas de pós-graduação em planejamento urbano e regional- são formatos curriculares desvinculados da agenda metropolitana e, como consequência, envereda-se na agenda local, privilegiando recortes espaciais e setoriais.

Como observado, a reforma do Estado ocorrida nos anos 1980, provocou um movimento no sentido da descentralização política-administrativa. Isso repercutiu sobre as leituras teóricas acerca do espaço e do papel do Estado. Os trabalhos no campo do planejamento urbano e regional enveredaram, como se verá a seguir, a respeito da problemática local, debruçando-se majoritariamente segundo a questáo da gestáo democrática das cidades - notadamente dos temas relativos aos instrumentos de regulação urbana e de mecanismos de gestáo participativa -, sobre questôes setoriais e, ainda, pelas porçóes do território metropolitano. Os estudos, em geral, deixaram em segundo plano a agenda metropolitana. Outros temas, como o desenvolvimento econômico e a sustentabilidade ambiental, também acompanharam o mesmo trajeto das políticas públicas estatais.

Acrescente-se, ainda, que a essa situação passam-se a somar duas grandes mudanças, ocorridas recentemente no Brasil: uma de natureza essencialmente econômica e, a outra, de natureza técnica e política.

É inegável que o novo modelo desenvolvimentista brasileiro inaugurou nos últimos dez anos, uma nova ordem urbana, que náo cancelou de todo a ordem préexistente, uma vez que ora a ela se sobrepóe, ora a ela se justapóe. O problema, porém, é que as metrópoles - não apenas as brasileiras, mas também as latino-americanas, cuja urbanidade já era fortemente questionada - assumem formas responsáveis por uma gama de riscos sociais, ambientais, políticos e culturais, decorrentes dessa nova ordem, norteada por princípios estruturadores, que se revelam em movimentos de fragmentação espacial e, simultaneamente, de integração espacial.

É inquestionável, também, que a recente política urbana nacional reforçou a atividade de planejamento urbano. O Estatuto da Cidade (2001) estabeleceu que os municípios com mais de 20.000 habitantes e os integrantes de regióes metropolitanas, de aglomeraçóes urbanas, de áreas de especial interesse turístico ou que se encontram em áreas onde estejam sendo desenvolvidos empreendimentos de impacto, são obrigados a elaborar seus respectivos Planos Diretores, a partir de processos participativos. Diante da exigência constitucional, o Ministério das Cidades passou a apoiar, técnica e financeiramente, a elaboração desses planos.

Evidentemente esses processos robusteceram, mais ainda, a perspectiva municipal e regionalista, inaugurada com a Carta Magna de 1988 e em detrimento, inclusive, da grande cidade metropolitana.

Os trabalhos constantes dos quatro últimos anais dos Encontros da Associação Nacional de Pós-graduação e Pesquisa em Planejamento Urbano e Regional (Anpur), realizados em 2005, 2007, 2009 e 2011, as dissertaçóes inscritas no vi Prêmio Brasileiro de Política Urbana e Regional, e as dissertaçôes e teses que participaram da viI versão desse Prêmio, espelham as duas grandes mudanças acima comentadas.

Quanto aos anais da Anpur, é notória a centralidade do tema relativo a planejamento e gestáo municipal participativa e, mais particularmente, aos processos de 
elaboração de Planos Diretores municipais. Sobre essa última questão, a academia esteve fortemente envolvida. Nos últimos encontros, aliás, o tema referente ao "Plano Diretor" esteve presente em Sessóes Livres. No Encontro de 2007, realizado em Belém, a Sessão coordenada pela professora Raquel Rolnik objetivou debater a relevância da participação da Universidade na avaliação desses processos. Explica-se a centralidade do tema Plano Diretor pela obrigatoriedade estabelecida pelo Estatuto da Cidade.

Cabe ressaltar que, no último Encontro da mencionada Associação, o tema alusivo à habitação foi bastante revigorado, na comparação com os três Encontros anteriores. Afinal, o novo modelo desenvolvimentista brasileiro impulsionou fortemente o mercado imobiliário de habitação. Foram, então, apresentados diversos trabalhos, versando sobre políticas habitacionais, instrumentos de acesso à moradia, sistemas de financiamento, articulação entre o capital imobiliário e o capital financeiro e implicaçóes das políticas habitacionais no processo de estruturação espacial das cidades, entre outros.

Outro tema de grande representatividade, no último Encontro, foi o desenvolvimento regional nas suas diversas escalas, à exceção da metropolitana. De fato, dos 122 trabalhos aprovados, apenas seis tratavam das áreas metropolitanas. Os demais tratavam de aglomeraçóes produtivas setoriais (polo moveleiro, vitivinícola, agronegócios...), rede urbana e desigualdades regionais, planejamento e gestáo regional, sob a ótica dos conselhos regionais.

Em termos gerais, pode-se afirmar que a questão metropolitana esteve marginalmente presente nos últimos Encontros da Anpur, ora abordada no âmbito de temas de maior abrangência, ora aparecendo setorialmente (bacias hidrográficas, transporte, emprego, inovação tecnológica...). Já o tema relativo à gestáo e governança metropolitana praticamente desapareceu, mobilizando poucos pesquisadores.

No que se refere aos Prêmios Política e Planejamento Urbano e Regional, os números de dissertaçóes de mestrado e de teses de doutorado são reveladores: das 40 dissertaçóes inscritas em 2009, apenas uma referia-se à metrópole - Brasília: metropolização e espaço vivido; nenhuma delas abordava a gestão e governança metropolitana. Em 2011, as dissertaçóes não contemplaram a problemática metropolitana: das 36 teses inscritas nenhuma tinha, como objeto de análise, essa temática; versavam sobre partes do território da metrópole ou sobre questóes setoriais (habitação, transporte, meio ambiente...). Todavia, o planejamento participativo, com ênfase nos processos de elaboração de Planos Diretores, foi tema presente em três dissertaçóes e quatro teses.

Esses números reforçam a ideia do quanto a política urbana brasileira tem orientado a pesquisa acadêmica. Ao mesmo tempo, denunciam que os programas de pós-graduação em planejamento urbano e regional não foram capazes de incorporar formatos curriculares capazes de responder a uma agenda metropolitana. Permaneceram reféns dessa política. Não responderam ao desafio teórico-metodológico imposto pelo novo formato do Estado e pela complexidade metropolitana. 


\section{Conclusóes}

Pode-se afirmar que, a questão da gestão das metrópoles dá lugar a uma série de controvérsias, tanto no debate acadêmico, quanto no debate político e da sociedade civil. Em termos gerais, situam-se, de um lado, os que defendem um novo modelo federativo, estabelecendo mecanismos de cooperação vertical entre os entes federados (União, Estados e Municípios), e articulações horizontais entre os municípios metropolitanos; do outro, os que se apoiam no argumento de um modelo baseado nas iniciativas voluntárias intermunicipais, à conta do receio da perda da autonomia adquirida pelos municípios metropolitanos, desde a Constituição de 1988.

No entanto, o maior desafio das metrópoles brasileiras é a sua construção, como espaços políticos, base para a constituição de arranjos institucionais de governança, capazes de mobilizar o Estado, o mercado e a sociedade civil, sem os quais elas ficarão à mercê de arranjos funcionais, que atendem a lógicas privatistas e fragmentadas dos atores econômicos e políticos. Com certeza, essa construção não se acomodará na regulação clássica, ou seja, nos arranjos tradicionais, nem tampouco nas iniciativas voluntárias intermunicipais.

Embora os sistemas de gestão, em nível nacional e municipal, tenham caminhado no sentido da democratização, o mesmo náo ocorreu em nível metropolitano, razão pela qual, para governar o espaço metropolitano, deve-se ir além do desenvolvimento da democracia local, voltando-se para o exercício de uma democracia metropolitana pautada na articulação entre os atores, visando à governabilidade do seu território. Essa articulação pode caminhar em várias direçóes, desde associaçóes transitórias, em torno de projetos comuns, a cooperaçóes que ultrapassem os perímetros urbanos metropolitanos, por meio da formatação de redes de colaboração, envolvendo interesses que extrapolem a fronteira metropolitana e, portanto, abarquem atores extrafronteira.

A questão central, porém, é a gestáo metropolitana, visando garantir um planejamento integrado da totalidade espacial metropolitana, capaz de contribuir para uma maior equidade social. Para tanto, são necessários arranjos institucionais verdadeiramente democráticos. Neste sentido, indaga-se: a introdução do sufrágio universal, com o fim de escolher gestores metropolitanos, náo contribuiria para gerar as condiçóes propícias a um efetivo governo democrático do território das metrópoles? Esse sufrágio não exigiria, por parte da população, uma consciência metropolitana? Ora, existe uma identidade metropolitana?

Como "sem dinheiro ninguém manda", é imperativa a autonomia financeira das instâncias democráticas metropolitanas. Esta, certamente, tem severas implicaçóes no formato do pacto federativo brasileiro. Se os entes metropolitanos náo têm capacidade de gestáo sobre os recursos públicos, como viabilizar uma governança democrática que possibilite o exercício da sua governabilidade? Náo seria o caso dos recursos para açóes de interesses comuns ficarem sob a alçada do governo metropolitano, e sua aplicação se dar de forma coerente com as necessidades dos municípios integrantes?

É relevante registrar que as formas institucionais de governança metropolitana não podem deixar de implicar a presença dos atores econômicos, notadamente da sua representação, na definiçãao das políticas que a eles concernem - crescimento e 
desenvolvimento econômico, construção de infraestrutura e equipamentos urbanos de caráter metropolitano. Os arranjos, inclusive, contribuiriam para que agissem espacialmente, sob a regulação do Estado. Afinal, essas políticas são de suma importância para o funcionamento dos territórios das metrópoles. Todavia, o que mais se assiste, na atualidade, é a mediação entre os interesses locais e globais.

Não resta dúvida de que a coalizão de forças políticas entre o Estado, os atores econômicos (representantes do mercado) e a sociedade civil, deve ser pautada pelos princípios da cooperação e da solidariedade democrática, guiados, por sua vez, pela transparência da ação governamental e pelo fortalecimento dos instrumentos de planejamento e controle social, no sentido do exercício de uma democracia metropolitana.

Importa relembrar que, o próprio termo regiáo (derivado do latim, régio, que remete a régere -reger, governar, dirigir, gerir, gerenciar- e, mais remotamente, a rex, régis-rei, governante, dirigente, gestor, gerente) sugere tratar-se de uma área sob o comando de um poder de natureza política, que a delimita, para administrar com eficiência, eficácia e efetividade.

As universidades, juntamente com os órgãos de fomento à pesquisa, podem e devem ter um papel importante nesse processo, mediante o estímulo aos estudos sobre a problemática metropolitana, em suas diversas dimensôes - social, econômica, política, administrativa, cultural e ambiental. É de esperar-se que esses estudos contribuam para resgatar a metrópole, enquanto autêntica regiáo, cujo funcionamento influencia não apenas o seu próprio processo de desenvolvimento, como também o de toda a nação brasileira. Isso exige, dos programas de pós-graduação em planejamento urbano e regional, novas grades curriculares que respondam a esse desafio.

\section{Referências bibliográficas}

Alves, R. de O. (2011). O estado, a multidão e os conflitos urbanos. DDR-Desenvolvimento Regional em Debate, 2(2), 111-112. Disponível em http://www.periodicos.unc.br/ index.php/drd/article/view/280

Arretche, M. (2000). Estado federativo e politicas sociais: determinantes da descentralização. Rio de Janeiro: Revan / São Paulo: Fundação de Amparo à Pesquisa do Estado de São Paulo (FAPESP).

Borba, S. V; Cunha, C. G. S. (2002). Dilemas da gestão cooperativa: o caso da/na Região Metropolitana. Cadernos Metrópoles, 7, 75-96, 10 sem. Disponível em http://revistas. pucsp.br/index.php/metropole/article/download/9260/6870

Bresser-Pereira, L. C. (2004). O novo desenvolvimentismo. Folha de S.Paulo, 19.9.2004. DisponívelemHTTP://WWW.BRESSERPEREIRA.ORG.BR/VIEW.ASP?COD=1454. Acessado em 13/12/2012.

Dupas, G. (2005). Atores e poderes na ordem global: assimetrias, instabilidade e imperativos de legitimação. São Paulo: Editora Universidade Estadual Paulista (UNESP).

Castells, M. \& Borja, J. (1996). As cidades como atores políticos (Trad. do espanhol: Omar Ribeiro Thomaz). Novos Estudos CEBRAP, 45 (julho), 152-166. Disponível em http://www.acsmce.com.br/wp-content/uploads/2012/10/AS-CIDADES-COMOATORES-POL\%C3\%8DTICOS.pdf 
Dallabrida, V. R. (2012). A administração se descentraliza, o poder nem tanto! Consideraçóes e percepçóes sobre experiências de descentralização político-administrativa no Brasil. Seminário da Rede Iberoamericana de Pesquisadores sobre Globalização e Território (RII). Belo Horizonte-MG. Disponível em http://www.unc.br/mestrado/docs/ArtigoADMINISTRACAO-SE-DESCENTRALIZA-RII.pdf

Dallabrida, V. R., Büttenbender, P. L. \& Birkner, W. M. K. (2011). A experiência de descentralizaçáo político-administrativa dos estados de Santa Catarina e do Rio Grande do Sul: concepçôes, percepções e síntese avaliativa. DRd-Desenvolvimento Regional em Debate. Canoinhas, 1(, n. 1), 40-64. Disponível em http://www.periodicos.unc.br/ index.php/drd/article/view/64

Harvey, D. (1996). Do gerenciamento ao empresariamento: a transformaçáo da administraçáo urbana no capitalismo tardio. Espaço \& Debates: Revista de Estudos Regionais e Urbanos, 39, 48-64. Disponível em http://bit.ly/QUWR48

Instituto de Pesquisa Econômica Aplicada (IPEA) (2011). Desafios contemporâneos na gestâo das Regiốes Metropolitanas. Comunicado do IPEA - 2011 - Outubro, n. ${ }^{\circ} 116$. Disponível em http://bit.ly/1h71BKn.

Leal, S. M. R. (2004a). Fetiche da participaçâo popular. Novas práticas de planejamento, gestáo e governança democrática no Recife, Brasil. Recife: CEPE.

Leal, S. M. R. (2004b). O novo capital social das cidades brasileiras. Caderno Metrópoles, 10 ( ${ }^{\circ} \mathrm{sem}$.), 55-74. Disponível em http://revistas.pucsp.br/index.php/metropole/article/view/9199

Leal, S. M. R. (2008). Territórios e escalas de cooperação e gestão consorciada: O caso francês e seus aportes à experiência brasileira, Cadernos Metrópoles, 20 ( $2^{\circ} \mathrm{sem}$.), 57-79. Disponível em http://revistas.pucsp.br/index.php/metropole/article/viewFile/8636/6423

Leal, S. M. R. (2011). Papel dos atores econômicos na governança das cidades brasileiras. Revista Movimentos Sociais e Dinâmicas Espaciais (Recife: UfPe / MSEU), 1(1), 62-82. Disponível em http://bit.ly/1iuhI4f

Lefèvre C. (2004). Paris et les grandes agglomérations occidentales: comparaison des modèles de gouvernance - Barcelone, Berlin, Lisbonne, Londres, Madrid, Manchester, Milan, Montréal, Rome, Stuttgart, Toronto. Paris: Mairie de Paris /Extramuros.

Melo, M. A. (2000). Gestão urbano-metropolitana: neomunicipalismo e empresarialismo local. Cadernos de Textos (Belo Horizonte: Fundação João Pinheiro e Escola de Governo), 2, 155-172.

Observatório das Metrópoles. Arranjos institucionais para a gestão metropolitana. Relatório de Pesquisa, outubro de 2009. Disponível em http://www.observatoriodasmetropoles. ufrj.br/relatorio_arranjos_gestao_metropolitana.pdf

Ribeiro, L. C. de Q., Tavares da Silva, É. \& Martins Rodrigues, J. (2011). Metrópoles brasileiras: diversificação, concentração e dispersão. Revista Paranaense de Desenvolvimento (Curitiba), 120, 171-201. Disponível em http://www.ipardes.pr.gov.br/ojs/index.php/ revistaparanaense/article/view/232

Rolnik, R. \& Somekh, N. (2004). Governar as metrópoles: dilemas da recentralização. In: L. C. de Q. Ribeiro (Org.), Metrópoles: Entre a coesão e a fragmentação, a cooperação e o conflito. São Paulo: Editora Fundação Perseu Abramo /Rio de Janeiro: FASE.

Rolnik, R. (2011). Será que a aprovação de um projeto de lei resolve o problema da gestão metropolitana? Blog da Raquel Rolnik. Disponível em http://raquelrolnik.wordpress. $\mathrm{com} /$ tag/gestao-metropolitana 